\title{
Modern Decision Support Systems in Oil Industry: Types, Approaches and Applications
}

\author{
Iakov S. Korovin * and Igor A. Kalyaev \\ Southern Federal University, 347928, Russian Federation, Rostov region, Taganrog, Chekhov street, 2 \\ ${ }^{*}$ Corresponding author
}

\begin{abstract}
In this paper we tried to perform a classification of modern decision support systems, applied in the oil industry, the methods and approaches implemented, the tasks and problems to be decided by the oil and gas production operators, applying these methods.
\end{abstract}

Keywords-decision support systems; oil industry; data mining; knowledge database disvovery; big data

\section{DeCision Support Systems ClassificAtion}

Generally, modern decision support systems (DSS) (DSS applied in oil industry are the typical ones) provide the following classification as follows.

By the interaction with the user:

- $\quad$ passive, that assist in the making decision process, but are not able to propose a discrete solution;

- $\quad$ active, that participate in the correct decision making;

- cooperative, that propose the DSS interaction with the user. The DSS decision can be improved by the user and after transmitted back into the system for checking. The decision will be provided until it's approved by the DSS user.

On conceptual level:

Communication-Driven DSS, that support the work of two or more users, proceeding the same task; processing;

Data-Driven DSS, that are targeted to access and data

Document-Driven DSS, that manipulate the unstructured information, stored in various electronic formats;

- Knowledge-Driven DSS, that provide the task solution on the basis of facts, rules, procedures.

Model-Driven DSS model driven, that use the access to statistic, financial and other models during their work; they handle both internal and external data;

By the application domain:

- $\quad$ task-oriented (desktop); small range systems, suitable for a single PC installation and one user usage.

These DSS are more simple than the distributed ones due to the absence of information exchange problem. The following types of task-oriented tasks are possible:

- the solution is automatically made by the system that consists of one node. Such system consists CPU, the system of automatic and/or manual information input and the decision performing device (the standard output device is possible). A fire extinguishing system, located on a dangerous object, can be an example of such system.

- the solution is made by the specialist, using the DSS. The system may include expert systems, modelling programs, the tools for results estimation and etc.

- distributed, that work with big data volumes and are applied by many users attached to big data storages.

The DSS of the type above mentioned can be distributed on territory either by functions. Geographically and functionally distributed DSS consist of calculation nodes, linked with each other, the every single of them is able to independently solve its local tasks, but none of them possesses enough knowledge, information and resources (or some of the list) in order to solve the common problem. A common problem, they can only solve together, combining their local capabilities and coordinating private decisions taken. Functionally distributed systems consist of several expert systems (or DSS), linked by information, or installed on a single computer;

\section{- hierarchical decision support system}

Hierarchical computational decision support system consist of expert systems and decision support systems, connected by the nodes of a single computer network. In terms of decisionmaking the given nodes units are unequal. The simplest example of such a system - a system consisting of subsystems $\mathrm{W}_{\mathrm{i}}, \mathrm{W}_{2}, \ldots, \mathrm{W}_{\mathrm{n}}$ of the $\mathrm{W}_{\mathrm{o}}$ subsystem of the second (higher) level.

The purpose of the $\mathrm{W}_{\mathrm{o}}$ subsystem - affect the lower subsystem so as to achieve the overall goal set for the entire system. Such a system can serve as a building block in constructing more complicated systems.

Objectively, there are the interests of the system as a whole. The $W_{o}$ subsystem acts as their spokesman. There are also the interests of $\mathrm{W}_{\mathrm{i}}, \mathrm{W}_{2}, \ldots, \mathrm{W}_{\mathrm{n}}$ subsystems, and their interests usually do not coincide with the interests of a subsystem $\mathrm{W}_{\mathrm{o}}$ in whole.

The degree of centralization of the system is determined by the measure of the separation of powers between the levels of the system. In cases where the Wo system can not make orders to the lower level subsystems, the subsystems of the lower level can not function without coordinating actions (for example, in the process of developing a new actions strategy or in the resources allocation), it is necessary to perform the agreed solutions 
Distributed DSS can have the following modifications:

- The decision is offered by several expert systems, situated on the same node, but estimating the situation the situation from different "points of view". They can offer a variety of solutions that should be corrected and approved by a specialist, sitting at the display unit;

- The decision is offered by several expert systems on different computing nodes of the network. Due to the fact that they can offer suitable computer solutions from different "angles", such solutions are to be considered by the experts from the various computing nodes. If one of the nodes passes not one but several solutions, the situation doesn't fundamentally change;

- the solution is offered by the some experts, located at the displays of different computer network nodes. They all will have to reconcile the final decision.

The variant, when the variety of solutions and is offered so by the expert system (s) as the expert (s), is possible, either.

Despite the fact that the specific implementation of the DSS depends much on the scope, methods of solutions generation, evaluation and approval are based on the same theoretical assumptions and methods.

By way of support:

- model-oriented, which access the statistical, financial or other models;

- based on the communications, that support the work of two or more people, engaged in a common task;

- focused on data that have access to the time series of the organization. They handle not only interior but the external data as well;

- focused on documents, that manipulate unstructured information, contained in various electronic formats;

- focused on knowledge that provide specialized solutions, based on facts. $\cdot$

\section{DSS Architecture}

Basically each DSS consists of two main components:

- data storage;

- analytical tools.

The data warehouse provides a single enterprise data storage environment, organized in structures that are optimized to perform analytical operations.

Analytical tools allow the user who does not have expertise in the field of information technologies, to fulfill navigation and presentation of the data in terms of subject area. For users of different qualification, DSS have different types of interfaces for accessing their services.

OLAP (On - Line Analitycal Processing) - is a tool for analyzing large amounts of data in real time. Working with OLAP-system, the user can implement a flexible view information, receive arbitrary data volumes and perform analytical operations of detailizing, convolution, distribution comparison over time. All work with the OLAP-system takes place in terms of subject area.

OLAP- systems are part of a more general concept of Business Intelligence, which includes in addition to the traditional OLAP-service means the organization of sharing documents, arising in the process of storage users. Business Intelligence technology provides the electronic exchange of accountant documents, the distinction between the rights of users, access to analytical information from the Internet and Intranet.

\section{A. Functional DSS}

These DSS are the simplest in terms of architecture. They are common for organizations which do not operate a global task and have a low level of information technologies development. A distinctive feature of functional DSS is that the data is analyzed being contained in the files of operating systems.

The advantages of such systems are compactness (because of the single platform usage) and efficiency (due to lack of the necessary data reload to a specialized system).

Disadvantages: narrowing of the range of issues that can be solved with the help of the system reduce of the data quality due to lack of a primary processing stage, increasing the load on the operating system with the possibility of its work termination.

\section{B. DSS, Using Independent Data Marts}

These systems are used in large organizations with multiple departments, including the IT. Each specific data mart is created to solve specific problems and is focused on a single circle of its users. This significantly improves system performance.

The implementation of such structures is basically simple. Speaking on the negative moments one can be note that the data is repeatedly input in different windows and may cause an overlap. This increases the cost of storing information and complicates the unification procedure. Filling data marts is rather difficult due to the fact that it is necessary to use multiple sources. There is no single picture of the organization's business, due to the fact that there is no definitive data consolidation.

\section{DSS Based on Two-Level Data Warehouse}

Such systems are applied in large companies where data is consolidated into a single system. Definitions and data processing methods in this case are unified. In order to provide the normal operation of such a DSS it is required to allocate a specialized team that will serve it.

This DSS architecture overcomes the drawbacks of the previous one, but within it there's no possibility to structure the data for individual user groups, as well as to restrict the information. There may be problems with the system performance.

\section{DSS Based on a Three-Level Data Store}

Such DSS use data warehouse which is transformed into data mart, used by specialists groups, solving similar tasks. 
Thus provides an access to both the specific structured data and to single consolidated information. Filling the data marts is simplified due to the use of approved and refined data, stored in a single source. There is a corporate data model. Such DSS distinguishes guaranteed performance. But there is also a severe data redundancy, which leads to increased demands on its storage. In addition, it is necessary to reconcile a similar architecture with a lot of areas possessing potentially different queries.

\section{E. Dynamic Modelling}

Dynamic modelling - is a methodology of analysis, in which the overall process is described in a mathematical model form in which all of the tasks and intermediate processes are presented as a system of interrelated indicators calculated

The method of dynamic modelling is used most often in conditions of inability to automate an entire class of processes, related to decision support systems, and the inability to take into consideration (applying traditional systems) the multivariance of the problems solutions.

Applying the dynamic modelling the company's business processes are described as a mathematical model, in which all tasks are presented as a system of interrelated calculated indicators. The particular importance is given to the overall combination of the factors, determining the successful implementation of all processes involved. So, the first step in the study the dynamic behaviour is a preliminary analysis of broad industrial aspects that contain a significant number of interactions.

The described method involves the construction of an iterative algorithm in the recursive actions simulation mode. It is peculiar - whatever the first initial decision is, all subsequent decisions must come from the state, resulting from the initial decision.

The object of dynamic modelling is a system in which the processes are described by differential equations, where the system or some of its elements are replaced with a model that possesses the dynamic properties similar to the original ones.

As mentioned above, the company is considered as a complicated system. In itself, the modelling provides a scientific basis, around which the controlled objects are grouped. The mathematical models apply method of establishing a causal relationship between any desired number of factors. Models indicate as the described system will evolve in time. The history of the oil and gas industry is especially important for the dynamic simulation, in particular, that part of it which relates to the specific decisions and the facts explanation, as well as the linear theory of information systems with feedback.

Visualized model creation allows to analyze the possible various processes' development directions, to discover and reflect the interdependence of these processes. For example, applying a dynamic modelling can provide:

- to estimate the effectiveness of space load, the usage of material resources;
- to analyze and model the impact of external factors on the efficiency of the enterprise as a whole, and in certain areas, and so on ..

Dynamic modeling, integrated with strategic planning, allows to build standalone applications that solve specific problems, taking into account built-in system simulation models of processes, and to display the modelling results on the specific dashboards, used in the process of decisionmaking support.

\section{F. DSS Features}

DSS offers to users:

- sequence of possible solutions in the descending order of ranking, until the manager ranks several decisions by himself;

- basic characteristics of the possible grade scales and criteria weights of the selected solutions, suitable to the manager ranking.

\section{G. DSS in the Oil Industry}

In general, the structure of the DSS in the oil industry is not different from the structures of systems used in other domains.

Estimating some corporative software solutions, it can be concluded that basically the developers apply the following methods and algorithms.

TABLE I. EXAMPLES OF OIL INDUSTRIAL SOFTWARE AND COINCIDING METHODS APPLIED (BEGINNING)

\begin{tabular}{|c|c|c|}
\hline Method, algorithm & Product & Company \\
\hline $\begin{array}{l}\text { Algorithms } \\
\text { - statistic } \\
\text { - deterministic }\end{array}$ & $\begin{array}{c}\text { Petrel } \\
\text { (Geophysics) }\end{array}$ & \multirow{4}{*}{ SIS } \\
\hline $\begin{array}{l}\text { Inversion search algorithms } \\
\text { Full-wave in reverse time } \\
\text { migration } \\
\text { Adaptive migration beams } \\
\text { Gaussian migration package } \\
\text { Finite-difference modelling }\end{array}$ & Omega & \\
\hline Ant tracking algorithm & $\begin{array}{c}\text { Structural } \\
\text { interpretation }\end{array}$ & \\
\hline \multirow{2}{*}{ Artificial neural networks } & Techlog & \\
\hline & DSS “ESP -NN” & $\begin{array}{l}\text { "Neuronetwork } \\
\text { technologies" } \\
\text { LTD }\end{array}$ \\
\hline Averaging method & $\begin{array}{l}\text { Advanced } \\
\text { Gridding and } \\
\text { Upscaling }\end{array}$ & \\
\hline $\begin{array}{l}\text { Methods } \\
\text { - Thomeer, } \\
\text { - Buckley-Leverett, } \\
\text { - Lambda, } \\
\text { - Wright-Wooddy-Johnson } \\
\text { - Hyperbolic Tangent }\end{array}$ & $\begin{array}{l}\text { Techcore } \\
\text { (Techlog) }\end{array}$ & \\
\hline $\begin{array}{ll}\text { Sequential } & \text { quadratic } \\
\text { programming } & \\
\end{array}$ & $\begin{array}{l}\text { Quanti.min } \\
\text { (Techlog) }\end{array}$ & \\
\hline Built in artificial intelligence & $\begin{array}{c}\text { GeoFrame } \\
\text { Geology Office }\end{array}$ & \\
\hline Statistic analysis & $\begin{array}{l}\text { StatPack (oil well } \\
\text { geology) }\end{array}$ & \\
\hline
\end{tabular}


TABLE II. EXAMPLES OF OIL INDUSTRIAL SOFTWARE AND COINCIDING METHODS APPLIED (THE END)

\begin{tabular}{|c|c|c|}
\hline Method, algorithm & Product & Company \\
\hline $\begin{array}{l}\text { Mathematic models } \\
\text { Algorithms } \\
\text { - parametric } \\
\text { - wave (non-parametric) } \\
\text { - transient regime algorithm } \\
\text { - spectral and cepstral } \\
\text { analysis, } \\
\text { - analysis based on Hilbert- } \\
\text { Huang transform and EMD- } \\
\text { method }\end{array}$ & Sirius DSS & $\begin{array}{l}\text { LTD "Vira } \\
\text { Realtime" }\end{array}$ \\
\hline $\begin{array}{l}\text { Modification of the Analytic } \\
\text { Hierarchy Process (AHP) - } \\
\text { integral method of } \\
\text { hierarchical analysis }\end{array}$ & Hysys, Hysim & Hyprotech Ltd \\
\hline Dynamic Simulation & Pro II, Provision & $\begin{array}{c}\text { Simulation } \\
\text { Sciences, Inc }\end{array}$ \\
\hline \multirow[b]{2}{*}{ Statistical modelling } & CHEMCAD III & $\begin{array}{l}\text { Chemstations, } \\
\text { Inc. }\end{array}$ \\
\hline & PROSIM & $\begin{array}{l}\text { Bryan Research } \\
\text { \& Engineering, } \\
\text { Inc. }\end{array}$ \\
\hline
\end{tabular}

\section{CONCLUSIONS}

1. As it can be seen from the above information, the software developers for oil industry apply artificial intelligence techniques, and therefore, we can talk about the application the industrial intelligent DSS.

This is justified in terms of the efficiency of the results, because in this industry basic requirements to the decision support systems applied are as follows:

- work in real time, under severe time constraints on decision-making, limited computing power, and the uncertainty associated with the incomplete and contradictory information being input;

- continuous, in the most cases, the operation mode;

- reduction of the operator involvement in the object control;

- real time diagnostics allowing to prevent the equipment failure.

2. Companies that have ready-made solutions for the industry, represent the possibility of "adaptation" of standard solutions for a specific user, using (including) into the methodology development as their own unique methods and algorithms, as well as the user tested ones.

Such a situation cannot provide to the researcher "pure" state of art for the proper analysis of methods and algorithms applied.

3. DSS in general, are under development. And here it should be borne in mind that presenting proprietary software solutions, developers are extremely sparsely speaking on the methodology applied in their products.

It is justified in terms of protection of copyright developments in the intellectual sphere.
It can be concluded that the topic of oil industry software methods is almost closed and the materials to make reliable and reasoned conclusions on are virtually absent.

\section{ACKNOWLEDGMENT}

This paper is published due the financial support of the Russian Science Foundation (RSF) via the grant № 15-1900196.

\section{REFERENCES}

[1] I.S. Korovin, M.V. Khisamutdinov. Neuronetwork decision support system for oilfield equipment condition online monitoring. Advanced Materials Research (Trans Tech Publications, Switzerland). Volume 902 (2014), Pages 409-415.

[2] I.S. Korovin, M.V. Khisamutdinov. Hybrid method of dynamograms wavelet analysis for oil-production equipment state identification. Advanced Materials Research (Trans Tech Publications, Switzerland. Volume 909 (2014).

[3] Korovin, Ya.S. Decision support system for electrical submersible pumps control on the neural network basis. Neftyanoe khozyaystvo - Oil Industry. Issue 1, January 2007, Pages 80-83.

[4] Korovin, Ya.S., Tkachenko, M.G., Kononov, S.V. Oilfield equipment's state diagnostics on the basis of data mining technologies. Neftyanoe khozyaystvo - Oil Industry. Issue 9, September 2012, Pages 116-118

[5] Korovin. I.S; Khisamutdinov M.V.; Kaliaev A.I. The Application of Evolutionary Algorithms in the Artificial Neural Network Training Process for the Oilfield Equipment Malfunctions' Forecasting. PROCEEDINGS OF THE 2ND INTERNATIONAL SYMPOSIUM ON COMPUTER, COMMUNICATION, CONTROL AND AUTOMATION Book Series: Advances in Intelligent Systems Research Volume: 68. Pages: 253-257. Published: 2013. 